\title{
National inequality and individual readiness to cooperate
}

\section{Joshua C. Skewes ${ }^{1,2 *}$}

1 - Department of Linguistics, Cognitive Science, and Semiotics, Aarhus University, Denmark

2 - Interacting Minds Centre, Aarhus University, Denmark

\begin{abstract}
People in societies with higher inequality spend less time volunteering, and participate less in social organizations. Nations with higher inequality spend less money on social welfare, and have more conflict. One reason for this may be that inequality affects how people make social decisions. Laboratory research has shown that when income inequality is simulated using cooperative economic games, people who are given more resources contribute less to their group than they should, and people who are given fewer resources contribute more. Groups with higher inequality thus generate less wealth overall, with poorer group members receiving the worst outcomes. This study links these experimental findings to real world inequality, and applies a model to explain these experimental effects in terms of social decision-making dynamics. Using a dataset from 255 groups playing a public goods game in thirteen economically diverse societies, I show that in nations with higher inequality, cooperation decays more quickly. I show that this occurs because people living in less equal nations have a lower readiness to match one another's contributions to a public good. I suggest possible psychological mechanisms underlying this tendency, and discuss the importance of these results for understanding trust and conflict in unequal societies.
\end{abstract}

*Corresponding author: Joshua C. Skewes, email: filjcs@ cas.au.dk, address: Jens Chr. Skous Vej 4, Building 1483, 3. 8000 Aarhus C, Denmark 


\section{National inequality and individual readiness to cooperate}

Regional and national inequality has been linked to a broad range of negative outcomes. When wealth and income are distributed less equally in a society, people are less cooperative (Cherry, Kroll, \& Shogren, 2005;

Nishi, Shiraldo, Rand, \& Christakis, 2015). They participate less in civic institutions (Costa \& Kahn, 2003) and there is lower adherence to civic norms (Knack and Keefer, 1997; Alesina \& La Ferrara, 2002). National inequality has been linked to decreased social trust (Fiske, Moya, Russell, \& Beams, 2012), poorer health outcomes (Pickett \& Wilson, 2015), and increased violent crime (Hsieh \& Pugh, 1993). At the extreme, national inequality may lead to violent conflict (Cramer, 2003; Krieger and Meierrieks, 2019; Piketty, 2013; Piketty, 2020).

People are therefore averse to inequality (Fehr \& Schmidt, 1999) and most report being happier in more equal societies (Alesina, Di Tella, \& MacCulloch, 2004; see however Starmans, Sheskin, \& Bloom, 2017). This may be because societies which are more equal are better able to increase collective welfare and to decrease resource conflicts by more efficiently providing public goods (Bouchey, 2019). At the policy level, countries with lower income inequality are more likely to favor more re-distributive fiscal policies (Lindert, 1996). At the civic level, communities with lower income inequality are more likely to have members who contribute to shared social and economic welfare (Goldin \& Katz, 1999; Costa \& Kahn, 2003; La Ferrara, 2002).

There is much research aimed at understanding how inequality is perpetuated. Most of this work is focused on inequality at the macroeconomic level. Proposed structural causes include economic policies that assume unsustainable rates of economic growth (Piketty, 2013); increased international wage competition (Krugman \& Venables, 1995); and structural changes in corporate financing (Fligstein \& Shin, 2004). Important work has also focused on how inequality is perpetuated by individual behavior. Proposed psychological causes include reduction of cooperation (Cherry, Kroll, \& Shogren, 2005; Nishi, Shiraldo, Rand, \& Christakis, 2015); stigmatization of poverty (Jachimowicz, Szaszi, Lukas, Smerdon, Prabhu, \& Weber, 2020); and the perception that the social environment is more competitive (Sánchez-Rodriguez, Willis, Jetten, \& Rodriguez-Bailón, 2019). The purpose of the present research is to establish a firm empirical connection between these structural and psychological levels of analysis (Granovetter, 2017), by showing how inequality at the national level has a clearly observable influence on individual's readiness to cooperate with others.

Experimental psychological research on this topic has mainly focused on the public goods game. In the experimental version of the game, a group of participants are given a fixed number of tokens, which they may either keep for themselves or contribute to a public good. All contributions to the public good are then multiplied by some factor, and redistributed to the participants. In the standard version of the game, the best outcome 
occurs for the group if all individuals contribute all of their tokens to the public good. If this happens, then the maximum number of tokens will be multiplied and returned to the individuals. However, the best outcome for each individual occurs if all other participants contribute all their tokens, while the individual themselves contributes nothing. The theoretical equilibrium for the game is therefore non-cooperation. What this means is that each individual has no better strategy than to invest all of their tokens in the private good, and to contribute nothing to the public good. In practice however, most participants split their tokens, and invest about half in the private good and half in the public good, with contributions declining as the game is repeated (Ledyard, 1995; Kopelman et al, 2002; Zelmer, 2003).

Bergstrom, Blume, and Varian (1986) used a mathematical model to analyze income inequality in the public goods game, and predicted that individuals with a higher income should optimally contribute more than individuals with a lower income. An experimental implementation of Bergstrom et al's model supported the predicted pattern of results (Chan, Mestelman, Moir, \& Muller, 1996). However, the authors found that individuals who were given more tokens on each round contributed substantially less than the model predicted, and individuals who were given fewer tokens contributed more than predicted. This result suggested that when incomes are unequal, richer individuals will contribute less than is strategically optimal for the group, and poorer individuals will contribute more than is optimal.

Subsequent experimental research has used simulated inequality in the laboratory to support this conclusion. In one experiment, people were paid different show-up fees as a way to artificially induce inequality in payoffs obtainable during the experiment, and this manipulation reduced the contribution and earnings of the whole group (Anderson, Mellor, \& Milyo, 2008). More recently, experimenters have shown that when inequality is combined with risk, peoples' pattern of contribution reverses relative to theoretical predictions, so that lower income individuals invest even more than higher income individuals (Vicens et al, 2018). Similar results have been reproduced in a wide range of lab settings, using different variants of the experimental pubic goods game, and different methods for simulating inequality (Tavoni, Dannenberg, Kallis, \& Löschel, 2011; Schlösser, Steiniger, Ehlebracht, and Fetchenhauer, 2020; Burton-Chellew, May, and West, S. A., 2013).

These results raise two main sets of questions. The first concerns the relationship between the experimental results and the effects of inequality observed in real world contexts. Unlike real world inequalities, experimentally induced inequalities are constrained in time and space to the laboratory. In real national economies, inequalities in wealth and income are pervasive, and are likely to impact a large proportion of individuals' economic decisions. Thus, it is important to investigate whether the lessons we have learned about 
cooperation by studying formal models and simulated inequalities in the laboratory also generalize to inequality experienced by individuals in their everyday lives.

This investigation is the first aim of the present project. I re-analyze open data from an experimental implementation of the public goods game played by groups from a range of economically diverse nations (Herrmann, Thöni, \& Gächter, 2008; Herrmann, Thöni, \& Gächter, 2017). To examine whether experimental results generalize to real world inequality, I correlate the earnings made by each group in the game with the Gini coefficient for the country from which the experimental participants were sampled. The Gini coefficient is a standard measure of income inequality in a society. Scores range from zero to 100, with zero indicating perfect income equality and 100 indicating perfect inequality. If stable income inequality undermines cooperation in the experimental public goods game, then groups from countries with higher Gini coefficients should earn less in the game, and should cooperate less across rounds played.

The second set of questions concerns the nature of the decision-making processes by which inequality undermines cooperation. In noting the discrepancy between model predictions and experimental results, experimental researchers have urged theorists to develop behavioral models to explain empirical departures from game theoretic equilibria (Chan et al, 1996). A range of behavioral models of the public goods game exist for this purpose (e.g. Camerer \& Ho; Erev \& Roth, 1998; Roth \& Erev, 1995; Fischbacher \& Gächter, 2002; Larrouy \& Lecouteux, 2017; Masel, 2007; see Skewes 2020 for review), however they have not yet been applied to investigating the effects of real world inequality on cooperation.

This investigation is the second aim of the present project. I develop a formal implementation of Fischbacher and Gächter's (2002) conditional cooperation schema (see also Skewes 2020) to explore how inequality in experimental participants' home country influences their social decision-making in the game. Core to this model is the idea that people have beliefs about what the rest of the group will contribute on an experimental round, as well as individualised preferences about what they should themselves contribute given those beliefs. For example, a more cooperative person may prefer to always match what they believe the rest of the group will contribute, whereas a less cooperative person may prefer to always under-match what they believe the rest of the group will contribute, thus saving more for themselves. If stable real world inequality undermines economic cooperation via stable effects on individuals' decision-making processes, then groups from countries with higher Gini coefficients should have less cooperative preferences as defined using this model. 


\section{Method}

\section{Dataset}

The data used in this study have previously been reported on by Herrmann, Thöni, and Gächter (2008), and the researchers have made the data freely available online (Herrmann, Thöni, \& Gächter, 2017). Participants in the experiment were asked to play a ten round public goods game. On each round, participants were allocated 20 tokens to keep or to contribute to the public good. On each round, all of the tokens contributed to the public good were multiplied by a factor of 1.4 , and the new total was redistributed to the participants. The game was completed by stable groups of four participants in each group.

280 groups participated in the experiment, for a total of 1120 participants. Data were collected from 15 economically and culturally diverse countries. These were Australia, Belarus, China, Denmark, Germany, Greece, Korea, Oman, Russia, Saudi Arabia, Switzerland, Turkey, the UK, Ukraine, and the USA.

Gini coefficients for the year 2009 were recovered from the United Nations Human Development Report (UN Development Program, 2009) for as many of the participant countries as possible. Gini coefficients were unavailable for Oman and Saudi Arabia, and so data collected from participants in these nations were not included in the analysis. Data from the other 13 countries were included. Only 25 groups were excluded from analysis for this reason.

The data included in the present analysis include 10 groups from Australia, 17 groups from Belarus, 24 groups from China, 17 groups from Denmark, 15 groups from Germany, 11 groups from Greece, 21 groups from Korea, 38 groups from Russia, 47 groups from Switzerland, 16 groups from Turkey, 14 groups from the UK, 11 groups from Ukraine, and 14 groups from the USA. Gini coefficients ranged from 25.3 (lowest inequality) to 41.9 (highest inequality).

\section{Data analysis and model specification}

I used Pearson correlation to investigate the relationship between national inequality and group earnings in the game. I calculated group earnings by adding all member contributions in a group, multiplying by the public goods multiplication factor of 1.4 , and then adding for all trials.

For all other analyses, I used Bayesian hierarchical modeling. This method allows us to simultaneously apply behavioral models to each participant at the individual level, while also modeling the relationship between inequality and individual model parameters at the group level. This approach is preferred, because it provides 
improved parameter estimates relative to the alternative two-step approach, in which we fit the models to each participant individually, and then run regression on participant level parameter estimates (Katahira, 2016).

In the first model, I investigated the direct effects of inequality on the rate of decay in individuals' contributions throughout the game. In the second model, I investigated the effects of inequality on readiness to cooperate, where this concept is formalized in a behavioral model of conditional cooperation (Fischbacher \& Gächter, 2010; Skewes, 2020).

The models are implemented using JAGS software (Plummer, 2003) via the R2jags package (Su \& Masano, 2012). All model code is available on the Open Science Framework (https://osf.io/f3e89/). For all models, I present the full posterior distributions for parameters of interest, as well as Bayesian credible intervals. For hypothesis tests, I present Bayes factors calculated as the Savage-Dickey density ratio (Lee \& Wagenmakers, 2014).

\section{Modeling decay in contributions}

To establish a basic effect of inequality on cooperation over time, I applied Bayesian hierarchical regression. This model assumes that each individual makes a decision about how much to contribute in the first round of the game, and that individual contributions decay across rounds (Ledyard, 1995; Kopelman et al, 2002). The individual level model assumes that decay occurs according to the equation:

$$
c_{g, s, t}^{\mu}=c_{g, s}^{0} \times e^{-\gamma_{s, g} \times t}
$$

where $c_{g, s, t}^{\mu}$ denotes the (mean of the prior distribution of the) contribution $c$ by an individual $s$ from group a $g$ on trial $t ; c_{g, s}^{0}$ represents the individual's initial contribution; and $\gamma_{s, g}$ represents the decay rate of the individual's contributions across trials.

The model assumes a linear relationship between national inequality (as represented using the Gini coefficient) and the two decay model parameters $c_{g, s}^{0}$ (starting contribution) and $\gamma_{s, g}$ (decay in contributions), such that

$$
c_{g, s}^{0}=\beta_{0}^{c}+\beta_{G i n i}^{c} \times \text { Gini }_{g}
$$

and

$$
\gamma_{s, g}=\beta_{0}^{\gamma}+\beta_{G i n i}^{\gamma} \times \text { Gini }_{g}
$$


where $\beta_{\text {Gini }}^{c}$ and $\beta_{\text {Gini }}^{\gamma}$ denote the effect of national Gini coefficients on individual participants' initial contributions and contribution decay rates; $\beta_{0}^{c}$ and $\beta_{0}^{\gamma}$ denote the group level model intercepts; and Gini $_{g}$ is the Gini score for the group (taken from national level data).

For model priors, I assume individuals' contribution amounts and regression model parameters follow standard normal distributions.

\section{Modeling conditional cooperation}

The conditional cooperation model was initially develop as an empirical description of cooperation behavior in public goods games by Fishbacher and Gächter (2010). The Bayesian hierarchical specification presented here is developed in Skewes (2020). The goal of the model is to identify and infer the effects of social dynamics within the group, on individual beliefs and preferences for cooperation.

Core to the model is the assumption that each individual has specific preferences for how much they would prefer to contribute on a round, given what they believe others will contribute. This can be expressed in the linear equation:

$$
P_{g, s}^{v e c}=B_{g, s}^{0}+B_{g, s}^{p} \times \text { token value }
$$

where token value is the list of all possible contribution amounts (i.e. 1 to 20 tokens), $B_{g, s}^{0}$ are $B_{g, s}^{p}$ are the intercept and slope of the model relating possible token amounts to contribution preferences for an individual $s$ in group $g$, and $P_{g, s}^{v e c}$ is the resultant vector of preferences.

This schema can be used to formalize different playing styles in the public goods game as follows. An individual with the intercept parameter $B_{g, s}^{0}=0$ and the slope parameter $B_{g, s}^{p}=0$ will prefer to contribute nothing when they believe others will, and their preferences will not change if they believe others will contribute any higher amount. Such an individual will be purely selfish. An individual with the intercept parameter $B_{g, s}^{0}=0$ and the slope parameter $B_{g, s}^{p}=1$ will prefer to contribute exactly what they believe others will, no matter the amount. Such an individual will be purely conditionally cooperative. An individual with the intercept parameter $B_{g, s}^{0}=0$ and the slope parameter $B_{g, s}^{p}<1$ will prefer to always contribute somewhat less than others, depending on the value of $B_{g, s}^{p}$. Such an individual will be partly selfish and partly conditionally cooperative. Exactly how cooperative they will be is represented by the magnitude of the parameter $B_{g, s}^{p}$ (bounded by zero and one). This parameter is therefore the target for inference in the present study. 
From this relationship, we assume that an individual's preferred contribution on a trial $P_{g, s, t}$ is determined by

$$
P_{g, s, t}=P_{G b_{g, s, t}}^{v e c}
$$

where $G b_{g, s, t}$ is an index that represents the individual's belief in how much the group will contribute on the trial.

The model assumes this belief is a product of learning over time, and is itself updated according to the learning rule

$$
G b_{g, s, t}=\gamma_{s, g} \times G b_{g, s, t-1}+\left(1-\gamma_{g, s}\right) G a_{g, s, t-1}
$$

where $G b_{g, s, t-1}$ denotes the individuals belief about others contribution on the previous trial, $G a_{g, s, t-1}$ denotes the average contribution observed on the previous trial, and $\gamma_{s, g}$ is a weighting or learning rate (between zero and one) for the influence of the two in the updating of beliefs. The learning rate parameter is assumed to vary between individuals.

The amount the individual decides to contribute is assumed to be a weighted combination of their preferences and beliefs so defined. The contribution on a trial $c_{g, s, t}$ is therefore modeled as

$$
c_{g, s, t}=\omega_{g, s, t} \times\left(G b_{g, s, t}\right)+\left(1-\omega_{g, s, t}\right) \cdot\left(P_{g, s, t}\right)
$$

where $\omega_{g, s, t}$ is the weighting factor governing the balance between beliefs and preferences. This parameter is itself expect to change over time, with preferences coming to dominate contribution choice as the game goes on, according to the equation

$$
\omega_{g, s, t}=\omega_{g, s, t-1} \times\left(1-\lambda_{s, g}\right)
$$

where $\lambda_{s, g}$ represents the rate at which preferences dominate for an individual.

For the learning rate parameter $\gamma_{s, g}$, and the rate parameter $\lambda_{s, g}$, I assume uninformative Uniform $(0,1)$ priors. I assume a preference intercept parameter $B_{g, s}^{0}=0$ for all participants. This corresponds to an assumption that whenever an individual believes others will contribute nothing, they will prefer to contribute nothing themselves. The preference slope parameter $B_{g, s}^{P}$ is the target for inference, and is included in the hierarchical regression. 


\section{Modeling the relationship between national inequality and conditional cooperation}

I used probit regression at the group level, to model the relationship between national inequality and willingness to cooperate. To implement this model, I assume a Beta distributions as a prior for the cooperativeness parameter $B_{g, s}^{P}$. A Beta distribution is appropriate, because the parameter can range from zero to one. I then re-parameterize the distribution to obtain the mean, such that

$$
\begin{gathered}
B_{g, s}^{P} \sim \text { Beta }_{\left(\text {Shape }_{g, s, 1}, \text { Shape }_{g, s, 2}\right)} \\
\text { Shape }_{1}=\mu B_{g, s}^{P}+\sigma_{g, s} \\
\text { Shape }_{2}=\left(1-\mu B_{g, s}^{P}\right)+\sigma_{g, s}
\end{gathered}
$$

and model the mean as a probit transformed linear effect of national Gini coefficient

$$
\operatorname{Probit}\left(\mu B_{g, s}^{P}\right)=\beta_{0}^{P}+\beta_{G i n i}^{P} \times \operatorname{Gini}_{g}
$$

where $\beta_{0}^{P}$ denotes the intercept of the effect of the model, and $\beta_{\text {Gini }}^{P}$ denotes the effect of national inequality on readiness to cooperate in the public goods game. For the group level parameters, I assume Normal distributions as priors. Gini coefficients were standardized before being entered into the model.

\section{Results}

There was a negative correlation between how much people earned in the game and the Gini coefficient of the country they played in $(r=-.21, p<.001)$. This suggests that in countries with higher income inequality, people generated less value in their groups.

The likely reason for this is that people contributed less over trials, as the game went on. This explanation is suggested by the Figure. Panel A shows raw contributions for all participants from countries in the bottom inequality quartile for the countries sampled (i.e. where Gini <31.6). Contribution amount is presented on the yaxis. Trial is presented on the $\mathrm{x}$-axis. Contribution amounts are over-plotted to indicate the frequency of each amount on each trial, so that more frequent contributions are represented as darker patches. Panel B presents the same data for participants from countries in the top inequality quartile (i.e. where Gini > 37.5). The figure suggests that both sets of countries had similar contributions at the start of the game, but that by about trial 4 , participants from countries with higher inequality were more frequently contributing fewer tokens. 
This impression is confirmed by the results of a hierarchical decay model applied to contribution amounts. To illustrate the overall trend, panel $\mathrm{C}$ of the Figure presents posterior predictions of decay in contributions for players from the country with the lowest Gini score (25.3, blue curve), and for players from the country with the highest Gini score (41.9, red curve). As the figure shows, the model predicts that contributions will start the same for each country, but that individuals will contribute less as the game progresses, and this effect will be more extreme if the group is from a country with higher inequality. The posterior distribution for the effect of inequality on initial contributions is presented in Panel D, and the distribution for the effect of inequality on decay in contributions is presented in Panel E. Bayesian hypothesis tests suggest strong evidence for no effect of inequality on initial contributions $(B F>100, C I=-.002$ to .006$)$, but strong evidence of an effect of inequality on decay $(B F>100, C I=.0026$ to .003$)$. This suggests that the effect of inequality is not on readiness to cooperate at the start of the game, but that in nations with higher inequality, cooperation breaks down more quickly.

The results of the conditional cooperation model suggest a possible mechanism underlying this result. Panel F of the Figure presents posterior predictions for contribution preferences, given others' contributions in the group. Players from the country with the lowest Gini score are represented in blue, players from the country with the highest Gini score are represented in red. The x-axis represents the range of contribution amounts possible on a trial, and the y-axis represents individuals' preferred contributions, given what they believe others will contribute. As the figure shows, the model predicts that individuals from countries with higher inequality prefer to contribute less than what they believe others will give.

This decrease in readiness to cooperate is supported statistically. Panel G shows the posterior distribution for the slope of the country with the lowest inequality. This distribution has a mode of about 0.98 , suggesting a preference for a close to 1-to-1 relationship between one's own and other people's contributions, or almost perfect conditional cooperation. Panel H shows the posterior for the slope of the country with the highest inequality. This distribution has a mode of about 0.88 , suggesting greater selfishness in contribution behavior, and a lowered preference for matching group contributions. The group level model provides strong evidence for an overall effect of Gini coefficient on the relevant model parameter $B_{g, s}^{p}$ (see Methods), with higher Gini coefficients predicting decreased readiness for cooperation $(B F>100, C I=-0.33$ to -0.14$)$. 

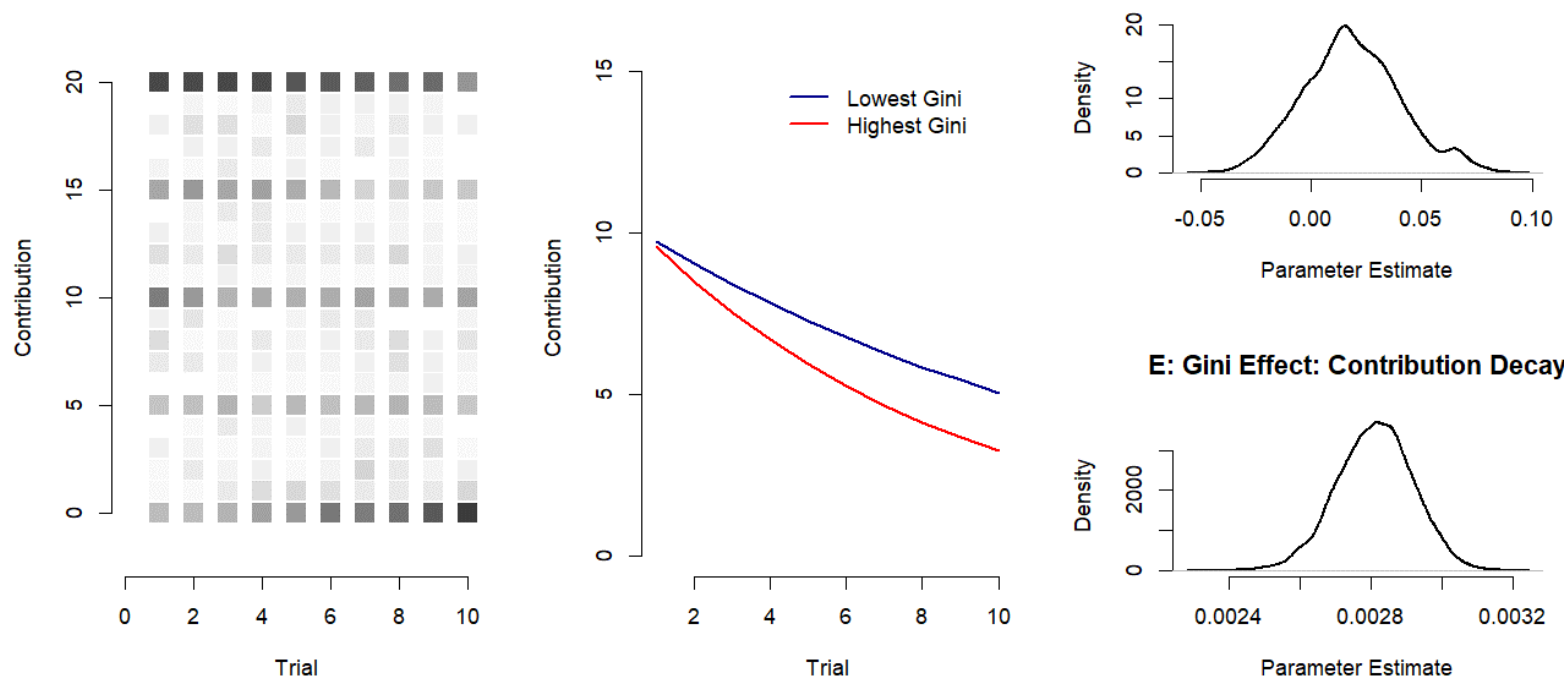

E: Gini Effect: Contribution Decay

B: Upper Quartile: Gini > 37.5

F: Posterior Preference Models
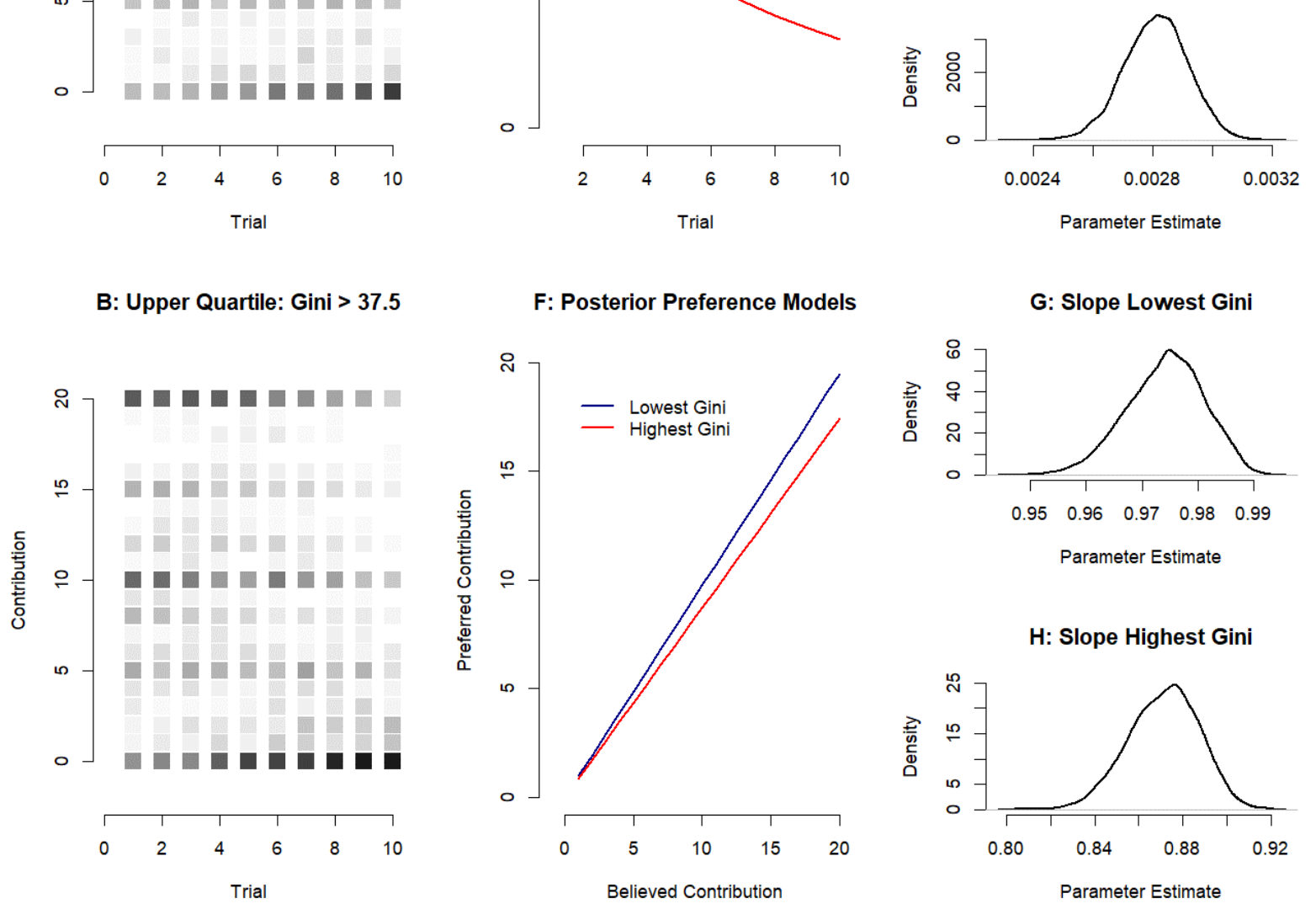

Figure: Panel A presents raw contributions for groups from countries in the lowest inequality quartile. Panel B presents raw contributions for groups from countries in the highest inequality quartile. Contributions are overplotted so that frequency for each amount on each trial is represented in the darkness of the patches. Panel C presents modelled contribution decay across trials for two the countries with the highest and the lowest Gini coefficients, and Panel D and E present posterior distributions for the overall effects of Gini coefficient on starting contributions and decay. Panel F presents modeled relationships between beliefs about others contributions, and ones own preferences for contributing, for the two countries with the highest and the lowest Gini coefficients, and Panels $\mathrm{G}$ and $\mathrm{H}$ present posterior distributions for the slopes of this relationship for these two countries. 


\section{Discussion}

The analysis shows that groups in countries with higher inequality earn less when playing together in public goods games. The reason they do this is that their contributions decrease more rapidly over trials, compared to people playing the game in less unequal countries. The reason for this is that people in countries with higher income inequality have a stronger preference to under-match the contributions of others in their group. Said another way, people in countries with higher inequality have a decreased readiness to cooperate with others economically, and the result is lower provision of the public good in the game.

This finding builds on existing laboratory research on inequality and public goods games. Previous experimental research has induced or simulated inequality, by for example using different show-up fees to simulate inequality in endowments (Anderson, Mellor, \& Milyo, 2008), or by providing different amounts of tokens on each trial to simulate income inequality (Schlosser et al, 2020). By comparing peoples' contributions to the public good across a range of societies with different Gini coefficients, the present research builds on these findings by investigating the effects of pre-existing inequalities between individuals from within different national communities.

This result suggests a behavioral process by which inequality might propagate in a society. This result also opens a range of important questions about the appropriate interpretation of this process, which should be the focus of future research. Answers to these questions may provide insights into how structural causes of inequality at the macroeconomic level influence individual psychology at the micro level. Such insights may be important for designing and implementing policies to reduce or even reverse adverse effects of income inequality.

One way to interpret this process is in terms of decreased trust (Chaudhuri, Sopher, \& Strand, 2002; Evans \& Krueger, 2016; Fiske, Moya, Russell, \& Bearns, 2012). The concept of trust has been associated with the expectation of future reciprocity, and the feeling of this expectation is generally understood to motivate cooperative behavior (Alós-Ferrer, \& Farolfi, 2019; Ostrom \& Walker, 2003; see however Chaudhuri, Sopher, \& Strand, 2002). Therefore, a possible interpretation is that by revealing a decreased willingness to cooperate in less equal societies, the present study reveals how decreased trust in those nations might lead to decreased efficiency in the provision of public goods. The study also suggests how such a dynamic might have a selfreinforcing effect. Lower expectations of reciprocity may decrease people's own readiness to cooperate, which may in turn lead to poorer use and development of public resources, leading to greater inequality, and further decreases in trust. When inequality becomes extreme enough, this may lead to related social problems, including violent conflict (Cramer, 2003; Krieger and Meierrieks, 2019; Piketty, 2013; Piketty, 2020). 
A limitation of this study is that it cannot be used to make inferences about these causal relationships. Inequality alone is unlikely to be sufficient to undermine reciprocity intentions. Mediating psychological and social processes are almost certainly involved (Granovetter, 2017). Recent research suggests two distinct processes that may play this role. The first is the effect of inequality on the perception of norms in the social environment. Sánchez-Rodriguez and colleagues have recently shown that inequality causes people to perceive the social environment as more individualistic and competitive (Sánchez-Rodriguez, Willis, Jetten, \& Rodriguez-Bailón, 2019), and that in unequal environments people are more likely to endorse values related to self-enhancement (Sánchez-Rodriguez, Rodriguez-Bailón, and Willis, 2020). If this is the case, then people might be motivated to under-match other's public goods contributions in order to fulfill competitive and self-enhancing social norms. The second psychological factor is the effect of inequality on negative perceptions of relative poverty, and on people's willingness and opportunity to draw on their social networks in times of economic hardship (Jachimowicz, Szaszi, Lukas, Smerdon, Prabhu, \& Weber, 2020). Such processes may lead people to develop a habit of under-matching other's public goods contributions, in order to maintain a higher relative status within their groups. Further cross-national research will be required to unravel how these processes interact with different drivers of structural inequality to produce the effects on social choice and behavior observed in the present study.

One criticism of the present research may be that the data are insufficiently representative. Importantly, Gini scores in the sample ranged from 25.3 to 41.9, and countries were sampled from Europe, East Asia, the United States, and Oceania. In the world's nations at present, the range of Gini scores is somewhat wider at the higher end, with a few countries in the 50-60 range. Despite these outliers, the natural diversity in inequality between countries is reasonably well represented in the data. Nevertheless, future research aiming to replicate and extend on these results should seek to obtain a broader sample, and to also include participants from communities in Africa, the Middle East, and Central, South, and South East Asia.

Another possible criticism is that the present data may conflate the effects of national income inequality with the effects of individual socioeconomic status or other individual differences. Ideally, the effects of individual socioeconomic differences should be included in the hierarchical models used in the present analysis (Jen, Jones, \& Johnston, 2009). Unfortunately, individual socioeconomic variables are not available in the present dataset. However, some care was taken to control for socioeconomic status in the original experiment (Hermann et al, 2008). The study included mostly university students, which was done not only for convenience, but in order to match participants as closely as possible across societies in terms of their socioeconomic background (Herrmann et al, 2008). Future research could incorporate a focus on inequality within societies, and seek also to model interactions between structural inequality and individual socioeconomic variables. 


\section{References}

Alesina, A., Di Tella, R., \& MacCulloch, R. (2004). Inequality and happiness: are Europeans and Americans different? Journal of Public Economics, 88(9-10), 2009-2042.

Alesina, A., \& La Ferrara, E. (2002). Who trusts others? Journal of Public Economics 85(2), 207-34.

Alós-Ferrer, C., \& Farolfi, F. (2019). Trust Games and Beyond. Frontiers in neuroscience, 13, 887.

Anderson, L. R., Mellor, J. M., \& Milyo, J. (2008). Inequality and public good provision: An experimental analysis. The Journal of Socio-Economics, 37, 1010-1028.

Bergstrom, T. C., Blume, L. E., \& Varian, H. R. (1986). On the private provision of public goods. Journal of Public Economics, 29, 25-49.

Bouchey, H. (2019). Unbound. How Inequality Constricts Our Economy and What We Can Do About It. Harvard University Press.

Burton-Chellew, M. N., May, R., \& West, S. A. (2013). Combined inequality in wealth and risk leads to disaster in the climate change game. Climatic Change, 120, 815-830.

Camerer, C., \& Ho, T. (1999). Experience weighted attraction in normal form games. Econometrica, 67(4), 827874.

Chadhuri, A., Sopher, B., \& Strand, P. (2002). Cooperation in social dilemmas, trust and reciprocity. Journal of Economic Psychology, 23(2), 231-249.

Chan, K. S., Mestelman, S., Moir, R., \& Muller, R. A. (1996). The voluntary provision of public goods under varying income distributions. The Canadian Journal of Economics, 29(1), 54-69.

Cherry, T. L., Kroll, S., \& Shogren, J. F. (2005). The impact of endowment heterogeneity and origin on public goods contributions: evidence from the lab. Journal of Economic Behavior \& Organisation, 57, 357-365.

Costa, D. L., \& Kahn, M. E. (2003). Understanding the American Decline in Social Capital, 1952-1998. Kyklos, $56,17-46$.

Cramer, C. (2003) Does inequality cause conflict? Journal of International Development, 15(4), 397-412.

Erev, I., \& Roth, A. E. (1998). Predicting how people play games. Reinforcement learning in experimental games with unique, mixed strategy equilibria. The American Economic Review, 88(4), 848-881. 
Evans, A. M., \& Krueger, J. I. (2016). Bounded prospection in dilemmas of trust and reciprocity. Review of General Psychology, 20(1), 17-28.

Fehr, E.; Schmidt, K.M. (1999). A theory of fairness, competition, and cooperation. The Quarterly Journal of Economics, 114(3), 817-68.

Fischbacher, U., \& Gächter, S. (2010). Social preferences, beliefs, and the dynamics of free riding in public goods experiments. American Economic Review, 100(1), 541-556.

Fiske, S. T., Moya, M., Russell, A. M., \& Bearns, C. (2012). The secret handshake: Trust in cross-class encounters. In S. T. Fiske \& H. R. Markus (Eds.), Facing Social Class: How Societal Rank Influences Interaction (p. 234-251). Russell Sage Foundation.

Fligstein N., \& Shin T. J. (2004). The shareholder value society: a review of the changes in working conditions and inequality in the United States, 1976-2000. In K. M. Neckerman (Ed.). Social Inequality. pp. 401-32. New York: Russell Sage Found.

Goldin, A., \& Katz, L. F. (1999). Human capital and social capital: The rise of secondary schooling in America 1910-1940. The Journal of Interdisciplinary History, 29(4), 683-723.

Granovetter, M. (2017). Society and Economy: Framework and Principles. Belknap Press.

Herrmann, B., Thöni, C., Gächter, S. (2008). Antisocial punishment across societies. Science, 319(5868), 13621367.

Herrmann, B., Thöni, C., \& Gächter, S. (2017). Data from: Antisocial punishment across societies. Dryad, Dataset

Hsieh, C., \& Pugh, M. D. (1993). Poverty, income inequality, and violent crime: A meta-analysis of recent aggregate data studies. Criminal Justice Review, 18(2), 182-202.

Jachimowicz, J. M., Szazi, B., Lukas, M., Smerdon, D., Prabhu, J., Weber, E. U. (2020). Higher economic inequality intensifies the financial hardship of people living in poverty by fraying the community buffer. Nature Human Behavior, 4, 702-712.

Jen, M. H., Jones, K., \& Johnston, R. (2009). Compositional and contextual approaches to the study of health behavior and outcomes: Using multi-level modelling to evaluate Wilkinson's income inequality hypothesis. Health \& Place, 15(1), 198-203. 
Kopelman, S., Weber, J. M., \& Messick, D. M. (2002). Factors influencing cooperation in commons dilemmas: A review of experimental psychological research. In National Research Council (Ed). The Drama of the Commons. Wachington D. C.: The National Academies Press. pp. 113-156.

Knack, S., \& Keefer, P. (1997). Does social capital have an economic payoff? A cross-country investigation. The Quarterly Journal of Economics, 112(4), 1251-1288.

Krieger, T., \& Meierrieks. (2019). Income inequality, redistribution and domestic terrorism. World Development, $116,125-136$.

Krugman, P, \& Venables, A. J. (1995). Globalization and the inequality of nations. The Quarterly Journal of Economics, 110(4), 857-880.

La Ferrara, E. (2002). Inequality and group participation: theory and evidence from rural Tanzania. Journal of Public Economics, 85, 235-273.

Larrouy, L., \& Lecouteux, G. (2017). Mindreading and endogenous beliefs in games. Journal of Economic Methodology, 24(3), 318-343.

Ledyard, J. O. (1995). Public goods: a survey of experimental research. In J. H. Kagel \& A. E. Roth (Eds.) The Handbook of Experimental Economics. Princeton N.J.: Princeton University Press. pp. 111-194.

Lee, M. D., \& Wagenmakers, E. J. (2014). Bayesian Cognitive Modeling: A Practical Course. Cambridge University Press.

Lindert (1996). What limits social spending? Explorations in Economic History, 33, 1-34.

Masel, J. (2007). A Bayesian model of quasi-magical thinking can explain observed cooperation in the public good game. Journal of Economic Behavior and Organization, 64, 216-231.

Nishi, A., Shirado, H., Rand, D. G., \& Christakis, N. A. (2015). Inequality and visibility of wealth in experimental social networks. Nature, 526, 426-429.

Ostrom, E., \& Walker, J. (2003). Trust and Reciprocity: Interdisciplinary Lessons For Experimental Research. The Russel Sage Foundation.

Pickett, K. E., \& Wilkinson, R. G. (2015). Income inequality and health: A causal review. Social Science \& Medicine, 128, 316-326.

Piketty, T. (2013). Capital in the Twenty-First Century. Harvard University Press. 
Piketty, T. (2020). Capital and Ideology. Harvard University Press.

Plummer, M. (2003). JAGS: A Program for Analysis of Bayesian Graphical Models Using Gibbs Sampling.

Proceedings of the 3rd International Workshop on Distributed Statistical Computing (DSC 2003), March 20-22, Vienna, Austria.

Roth, A., \& Erev, I. (1995). Learning in extensive form games: experimental data and simple dynamic models in the intermediate term. Games and Economic Behavior, 8, 164-212.

Sánchez-Rodríguez, Á., Rodríguez-Bailón, R., Willis, G.B. (2020), Economic inequality affects perceived normative values. Group Processes \& Intergroup Relations, 1-16.

Sánchez-Rodríguez, Á., Willis, G.B., Jetten, J., \& Rodríguez-Bailón, R. (2019), Economic inequality enhances inferences that the normative climate is individualistic and competitive. European Journal of Social Psychology, 49, 1114-1127.

Schlösser, T., Steiniger, T., Ehlebracht, D., \& Fetchenhauer, D. (2020). The effect of democratically determined (In)equality on cooperative behavior. Kölner Zeitschrift för Soziologie und Sozialpsychologie, 72, 33-54.

Skewes, J. C. (2020). Choice in shared resource problems: a social motives selection model. PsyarXiv Preprints. https://psyarxiv.com/f6vrx/.

Starmans, C., Sheskin, M., \& Bloom, P. (2017). Why people prefer unequal societies. Nature Human Behaviour, 1(4), 0082.

Su, Y.-S., \& Masano, Y. (2012). R2jags: A Package for Running jags from R (Version R package version 0.0308) [Computer software]. http://CRAN. R-project.

Tavoni, A., Dannenberg, A., Kallis, G., \& Löschel, A. (2011). Inequality, communication, and the avoidance of disastrous climate change in a public goods game. Proceedings of the National Academy of Sciences, 108(29), 11825-11829.

United Nations Development Programme (UNDP 2009). Human Development Report.

Vicens, J., Bueno-Guerra, N., Gutiérrez-Roig, M., Garcia-Lázaro, C., Gómez-Gardeñes, J., Perelló, J., Sánchez, A., Moreno, Y., \& Duch J. (2018). Resource heterogeneity leads to unjust effort distribution in climate change mitigation. PLoS ONE, 13(10).

Zelmer, J. (2003). Linear public goods experiments: A meta-analysis. Experimental Economics, 6, 299-310. 